Chapter 13

\title{
Application of Mobile RFID-Based Safety Inspection Management at Construction Jobsite
}

\author{
Yu-Cheng Lin, Yu-Chih Su, Nan-Hai Lo, \\ Weng-Fong Cheung and Yen-Pei Chen \\ Additional information is available at the end of the chapter \\ http://dx.doi.org/10.5772/53176
}

\section{Introduction}

Jobsite safety management is very important subject special in construction management. Managing jobsite safety-related inspection information plays an important role in the view of safety management. Managing jobsite safety management effectively is extremely difficult owing to various participants and environments in construction jobsite. With the advent of the Internet, web-based information management solutions enable information dissemination and information sharing at the construction jobsite. Generally, jobsite safety-related managers and engineers require access to the important check locations to handle inspection work in construction jobsite. However, jobsite safety-related managers and engineers generally use sheets of paper to handle various types of inspection checklists and entry check record. Consequently, there is serious rework progress regarding the data capture and entry in inspection progress. Furthermore, current desktops and notebooks are not suitable for inspection work at the jobsite because of problems in transportability.

In order to solve the above problems, this study presents a novel system called Mobile RFID-based Safety Inspection Management (RFIDSIM) system for jobsite safety management and providing safety inspection information sharing platform among all participants using web technology and RFID technology. The RFIDSIM is then applied in a construction commerce project jobsite in Taiwan to verify our proposed methodology and demonstrate the effectiveness of safety inspection progress in construction jobsite. The combined results demonstrate that, a RFIDSIM system can be a useful web safety inspection management platform by utilizing the RFID approach and web technology. 
Integrating Near field communication (NFC) technology and mobile devices such as NFC Smartphone, Radio Frequency Identification (RFID) scanning and data entry mechanisms, can help improve the effectiveness and convenience of information flow in the safety inspection management. The combined results demonstrate that, an RFIDSIM system can be a useful mobile RFID-based jobsite safety management platform by utilizing the NFC and web technologies. With appropriate modifications, the RFIDSIM system can be utilized at any jobsite inspection and management progress for jobsite safety management divisions or suppliers in support of the RFIDSIM system.

\section{Problem statement}

Jobsite safety management performance can be enhanced by using RFID technology for information sharing and communication. There are many jobsite safety checkpoints locations need for tracked and inspected for jobsite safety management. Information acquisition problems in inspection management follow from information being gathered from jobsite safety checkpoints locations. The effectiveness of information and data acquisition influences the efficiency of jobsite inspection management. Usually, project managers and safety staff members generally use sheets of paper and/or field notes for jobsite safety inspection progress in Taiwan construction jobsite. Restated, existing means of processing information and accumulating data are not only time-consuming and ineffective, but also compromise jobsite safety management in information acquisition. Such means of communicating information between jobsite safety checkpoints locations and jobsite office, and among all participants, are ineffective and inconvenient. The primary problems in inspection regarding to data capture and sharing based on experts interviews are as follows: (1) the efficiency and quality are low, especially in the safety inspection progress in construction jobsite through document-based media, (2) there are serious rework progress regarding the data capture and input in safety inspection progress, and (3) there are serious problems regarding to inspection information collection and responding during safety inspection progress. However, few suitable platforms are developed to assist jobsite office with capturing and sharing the jobsite safety inspection information when jobsite office needs to handle inspection information and inspection management work. Therefore, to capture data effective and enhance inspection information collection and respond in construction jobsite will be primary and significant challenge in the study.

\section{Research objectives}

This study utilizes the RFID and web technology to enhance the inspection management progress and effectiveness in jobsite safety management. This system is controlled by the management division, and provides project managers and safety staff members with realtime checkpoints-related information-sharing services, enabling them to dynamically re- 
spond to the entire jobsite safety management network. This study develops Mobile RFIDbased Safety Inspection Management (RFIDSIM) system to improve efficiency and costeffectiveness of jobsite safety management, improve practical communication among participants, and increase flexibility in terms of service delivery and response times. RFIDSIM system is a web-based system for effectively integrating managers, safety staff members and relative members, to enhance the jobsite safety management in the construction. Utilizing smartphone with NFC technologies can extend RFIDSIM systems from offices to jobsite safety checkpoints locations. Data collection efficiency can also be enhanced using RFID-enabled smartphone with NFC technology to enter and edit data on the jobsite safety checkpoints locations. By using web technology and RFID-enabled smartphone with NFC technologies, the RFIDSIM system for the management division has tremendous potential to increase the efficiency and effectiveness of information respond and management, thus streamlining services jobsite safety management processes with other participants. The portal and RFID-enabled smartphone with NFC technology enable safety staff members to update data from the jobsite safety checkpoints locations and immediately upload it to the system; project managers can receive inspection information and make better decisions regarding future jobsite safety management and control. The main purposes of this study include (1) developing a framework for a mobile jobsite safety inspection system; (2) applying such a system that integrates RFID-enabled smartphone with NFC technology to increase the efficiency of safety inspection data collection in the jobsite, and (3) designing a webbased portal for jobsite safety management and control, providing real-time information and wireless communication between jobsite office and jobsite safety checkpoints locations. Figure 1 illustrates solutions used in a polite test utilized RFIDSIM system in Taiwan construction jobsite. With appropriate modifications, the RFIDSIM system can be utilized at any jobsite safety inspection and management application in construction.

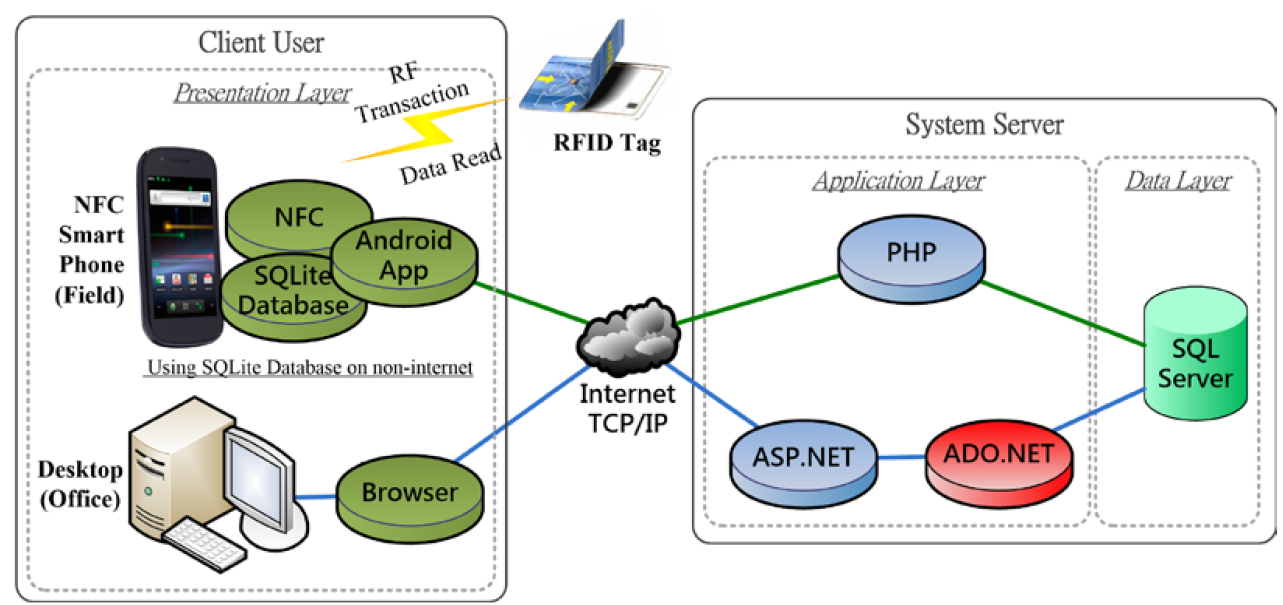

Figure 1. RFIDSIM System Framework Overview 


\section{Background research}

RFID is an automatic identification solution that streamlines identification and data acquisition, operating similarly to bar codes. Automatic identification procedures have recently become very popular in numerous service industries for purchasing and distribution logistics, and in manufacturing companies and material flow systems. Jaselskis and Anderson (1995) investigated the applications and limitations of RFID technology in the construction industry, and attached read/write RFID tags to the surfaces of concrete test that were cast from the job site to test lab. This RFID technology has been widely applied in many areas in the construction industries for the following reasons: (1) to provide owners and contractors with information to enhance operation using RFID technology (Jaselskis and Tarek, 2003); (2) to propose a novel concept of "parts and packets unified architecture" in order to handle data or information related to a product carried by product itself by utilizing RFID technology (Yagi et al., 2005); (3) to apply RFID technology as a solution to problems in pipe spools, and identify potential economic benefits from adopting RFID technology in automated tracking (Song et al., 2006); (4) to apply RFID combined with GIS technology in order to locate precast concrete components with minimal worker input in the storage yard (Ergen et al., 2006); (5) to improve the efficiency of tracing tools and tool availability using RFID (Goodrum et al., 2006); (6) to develop mobile construction supply chain system integrated with RFID technology (Wang et al., 2006); (7) to describe a prototype of an advanced tower crane equipped with wireless video control and RFID technology (Lee et al., 2006); (8) to improve tracing of material on construction using materials tagged with RFID tags (Song et al., 2006); (9) to present strategy and information system to manage the progress control of structural steel works using RFID and 4D CAD (Chin et al., 2008); (10) to enhance precast production management system integrated with RFID application (Yin et al., 2009), and (11) to present a new methodology for managing construction document information using RFID-based semantic contexts (Elghamrawy and Boukamp, 2010).

The use of technology to improve delivery process control is not a novel concept. Many industries have applied barcodes to track materials for many years. Construction companies began to examine the use of barcodes for tool management in the early 1990s. Although barcode is an established and affordable technology, it has presented problems in the construction industry due to the short read range and poor durability of barcodes - a barcode requires a line of sight, and becomes unreadable when scratched or dirty.

An RFID system is composed of an RFID tag and an RFID reader. The RFID tag comprises a small microchip and an antenna. Data are stored in the tag, generally as a unique serial number. The RFID tags can be either passive (no battery) or active (battery present). Active tags are more expensive than passive tags and have a read range of 10-100 meters. Passive tags have a read range of $10 \mathrm{~mm}$ to approximately $5 \mathrm{~m}$ (Manish and Shahram, 2005). The vast majority of RFID tags applied in the construction industries are passive.

The RFID reader functions as a transmitter/receiver. The reader transmits an electromagnetic field that "wakes up" the tag and provides the power required for it to operate (Lahiri, 2005). The tag then transfers data to the reader via the antenna. This data are then read by 
the RFID reader, and transferred to a Pocket PC or computer. Unlike barcodes, RFID tags do not require line-of-sight to be read; they only need to be within the reader's radio range. Additionally, RFID tags can be read through most materials. RFID tags are shrinking, with some measuring only $0.33 \mathrm{~mm}$ across. Although RFID systems can apply different frequencies, the most common frequencies are low $(125 \mathrm{KHz})$, high $(13.56 \mathrm{MHz})$ and ultra-high (UHF) (850-900MHz) (Lahiri, 2005).

RFID (Radio Frequency Identification) is a tagging technology that is gaining widespread attention due to the great number of advantages that it offers compared to the current tagging technologies being used today; like barcodes. Near Field Communication, or more commonly known as NFC, is a subset of RFID that limits the range of communication to within 10 centimetres or 4 inches. Compared with Bluetooth and infrared, the main characteristic of NFC is quick, easy, security. Although the NFC data transmission speed is far less than the Bluetooth and infrared, the device only by the unilateral power supply to the operation of the device near to the rapid induction features, and greatly enhance the ease of use. Furthermore of the NFC device requires very short communication distance. NFC technologies help to improve data security because it can reduce the data to the risk of being intercepted or stolen.

In recent years, due to the rapid development and popularization of the smartphone, a growing number of mobile phone NFC functionality into the standard features. The NFC-enabled mobile phone through the sensor to read high-frequency band RFID tags or other NFC-enabled devices for data transmission via a simple touch can, and are widely used in the identification, communication, information obtained, consumption and other purposes provide fast and convenient communication, this study using NFC phones used in patrol operations and identification of the site staff can enhance the operating convenience of mobility and reduce the cost of equipment to build, in order to improve the job the best solution.

Notably, RFID systems are one of the most anticipated technologies that will potentially transform processes in the engineering and construction industries. In the construction industry, RFID technology can be utilized with smartphone, thereby allowing staff members to integrate seamlessly safety work processes in the jobsite, due to the ability to capture and carry data. With a NFC technology plugged into a smartphone, the RFID-enabled smartphone is a powerful portable data collection tool. Additionally, RFID readings increase the accuracy and speed of information communication, indirectly enhancing performance and productivity.

The advantages of using mobile devices in the construction industry are well documented (Baldwin et al., 1994; Fayek et al., 1998; McCullough, 1997). Moreover, mobile devices have been applied in numerous construction industries, to provide the following support: (1) providing wearable field inspection systems (Sunkpho and Garrett, 2003); (2) supporting pen-based computer data acquisition for recording construction surveys (Elzarka and Bell, 1997); (3) supporting collaborative and information-sharing platforms (Pena-Mora and Dwivedi, 2002); (4) using mobile computers to capture data for piling work (Ward et al., 2003), and (5) utilizing mobile devices in construction supply chain management systems (Tserng et al., 2005). 


\section{System implementation}

The RFIDSIM system has three main components, a smartphone, RFID and a portal. Significantly, both the smartphone and RFID components are located on the client side, while the portal is on the server side. All inspection-related information acquired by safety staff members within the RFIDSIM system is recorded in a centralized RFIDSIM system database. All staff members can access required information via the portal based on their access privileges. The RFIDSIM system extends the jobsite safety management from the jobsite office to safety checkpoint locations to assist with safety inspection services, while the RFIDSIM system primarily deals with data transactions in all departments or systems integration. The RFIDSIM system consists of a mobile inspection management portal integrated with RFIDenabled smartphone and RFID technology. Each module is briefly described below.

\subsection{RFID subsystem of RFIDSIM system}

The RFID technology can be either a passive or active system. The major difference between an active and a passive RFID system is that an active tag contains a battery, and can transmit information to the reader without the reader generating an electromagnetic field. The case study uses HF passive RFID technology due to budget restrictions and short distance read range requirement.

\subsection{Mobile device (smartphone) subsystem of RFIDSIM system}

The RFIDSIM system adopts Google Nexus S as the RFID-enabled smartphone with NFC technology (see Fig. 2). The Google Nexus S runs the Android operating system. All data in the smart phones are transmitted to the server directly through the web via Wi-Fi. Google Chrome was chosen as the web browser in the RFID-enabled Google Nexus S.

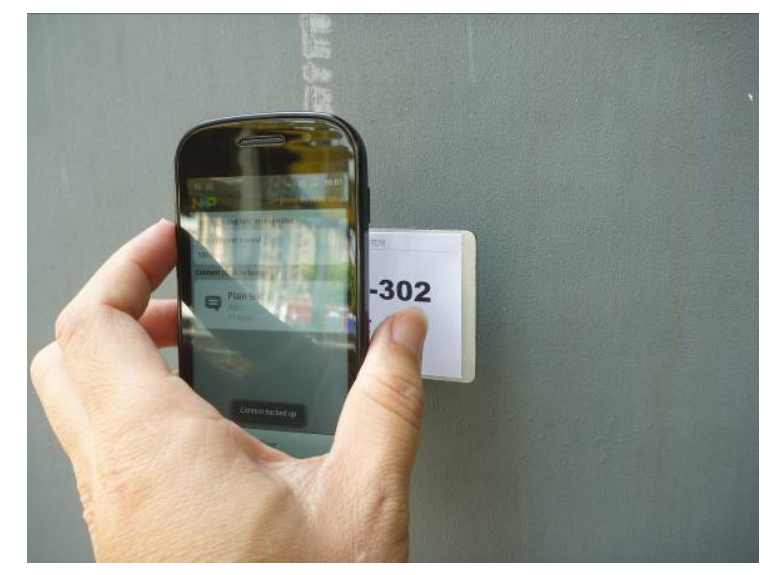

Figure 2. displayed the RFID-enabled smartphone with NFC technology and HF RFID tags using in the study. 


\subsection{Web portal subsystem of RFIDSIM system}

The web portal is an information hub in the RFIDSIM system for a jobsite safety management. The web portal enables all participants to log onto a single portal, and immediately obtain information required for planning. The users can access different information and services via a single front-end on the Internet. For example, a project manager can log onto the portal, enter an assigned security password, and access real-time jobsite safety inspection information and result. The web portal of RFIDSIM system is based on the Microsoft Windows Server 2008 operating system with Internet Information Server (IIS) as the web server. The prototype was developed using ASP.NET, which are easily combined with HTML and JavaScript technologies to transform an Internet browser into a user-friendly interface. The web portal provides a solution involving a single, unified database linked to all functional systems with different levels of access to information.

The following section describes the implementation of each module in the RFIDSIM system.

\subsection{Inspection module}

Safety staff members can enter inspection results directly via a smartphone. Additionally, smartphone display the inspection checklist in the each jobsite checkpoint location. Safety staff members can record inspection information for conditions, inspection result, descriptions of problems and suggestions that have arisen during the progress. The module has the benefit that safety staff members can enter/edit inspection results, and all records can be transferred between the smartphone and portal by real-time synchronization, eliminating the need to enter the same data repeatedly.

\subsection{Progress monitor module}

This module is designed to enable project manager and safety staff members to monitor the progress of inspections management. Additionally, project manager and safety staff members can access the progress or condition of jobsite safety checkpoints locations. The progress monitor module provides an easily accessed and portable environment where project manager and safety staff members can trace and record all safety-related inspection information regarding the status of inspections of safety checkpoints locations.

\section{Polite test}

This study is applied in Taiwan construction jobsite for the polite test. The construction building base was located in the Taipei metropolitan area, near MRT stations and public facilities. The construction project include 30 floors steel reinforced concrete structure buildings, underground parking and five floors of public space. There are three main buildings in the project. The project includes corporate headquarters, office buildings, and a business hotel. This study utilizes an RFIDSIM system in the jobsite safety inspection management. Existing approaches for tracking and managing safety inspection adopt manually updated paper-based records. The most of inspection work were paper-based work by manual entry although construction management system was developed for information management. 
However, information collected by staff members using such labor-intensive methods is rework and ineffective in the inspection results entry. Therefore, jobsite safety management division and safety staff members utilized the RFIDSIM system to enhance safety inspection and jobsite safety management in the case study. HF Passive read/write RFID tags were used in the case study. After the critical safety checkpoint locations were selected, each HF RFID tag for the safety checkpoint location was made, and the unique ID of safety checkpoint was entered into the RFIDSIM system database. After the safety checkpoint location was assigned to be monitored for safety inspection, the safety checkpoint location was scanned with a RFID tag to enter the RFIDSIM system. During the setup phase, all the ID of safety checkpoint in the RFID tag had been determined and entered the database for system, and then the RFID tag was attached in the safety checkpoint location (see Figs. 3 and 4). Finally, the tag will be scanned and checked before the inspection work.

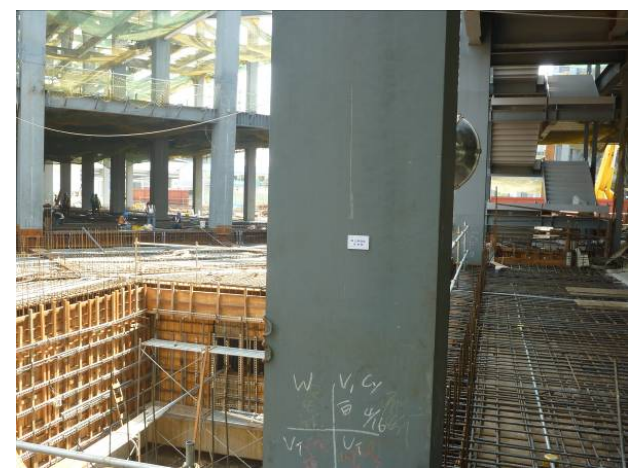

Figure 3. Displayed the safety checkpoint location attached UHF RFID tag in the case study. (A)

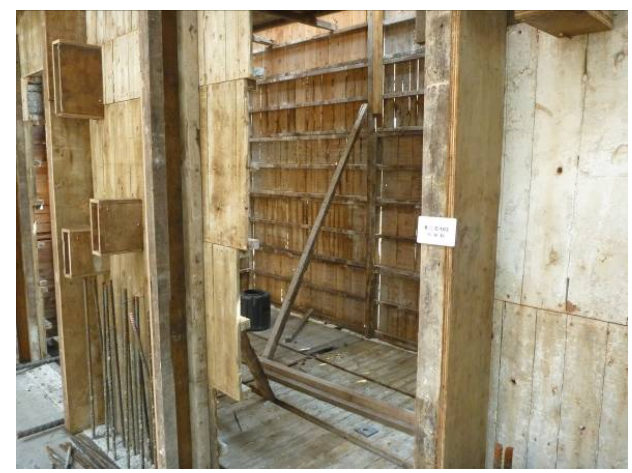

Figure 4. Displayed the safety checkpoint location attached UHF RFID tag in the case study. (B)

Before the inspection work, the safety staff members can check the inspection list from smartphone, refer the relative information and can make the preparation work without 
printing any paper document. During the inspection progress, the safety staff member scanned the RFID tag first and to select the inspection result (see Figs. 5 and 6). The system would update inspection information of jobsite safety checkpoints location via browser under wireless circumstance. After the jobsite safety checkpoints locations were inspected, staff members recorded the status and execute the work by procedure. After the operation, safety staff member recorded the result of inspection, edited the description in the smartphone, and provided the updated information to the system (see Fig. 7). Finally, the safety manager and the authorized staff members accessed the updated information from jobsite office synchronously. Fig. 8 displayed the process flowchart of RFIDSIM system. Fig. 9 displayed safety staff used RFID-enabled smartphone to scan RFID tags and edited the description in the smartphone. Fig. 10 displayed project manager entered the RFIDSIM system and accessed the safety inspection result.

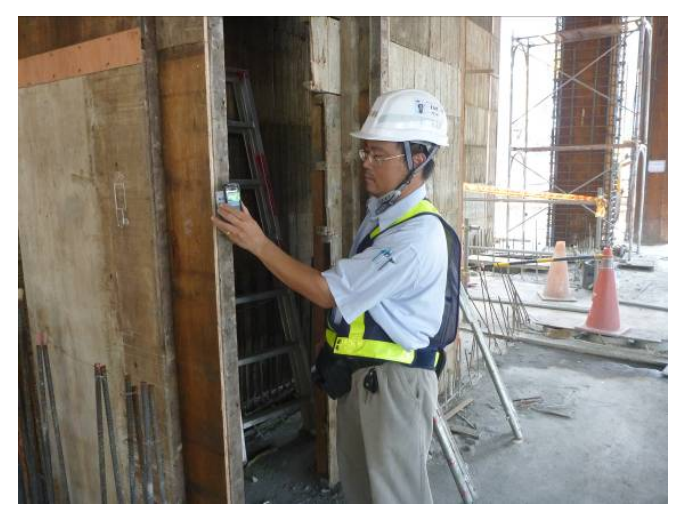

Figure 5. Displayed safety staff used RFID-enable smartphone to scan RFID tag. (A)

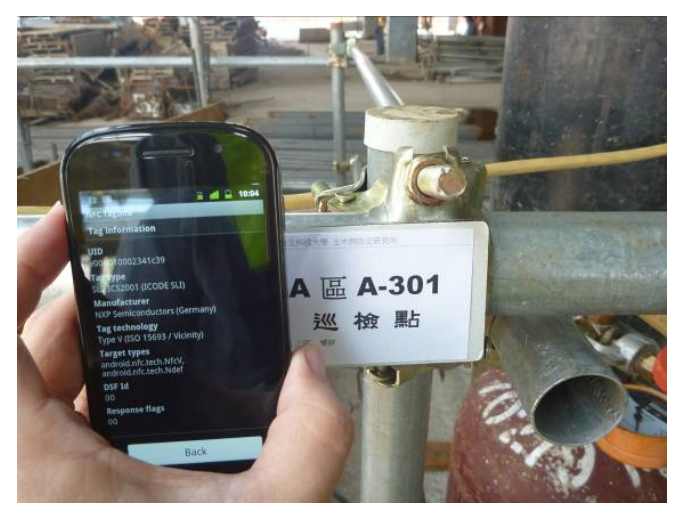

Figure 6. Displayed safety staff used RFID-enable smartphone to scan RFID tag. (B) 


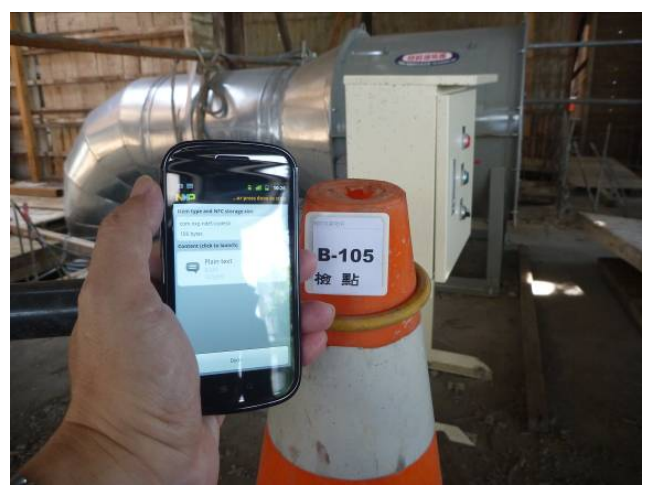

Figure 7. Ssplayed the staff updated the inspection information in jobsite checkpoint location

\section{Field tests and results}

Overall, the field test results indicate that HF passive RFID tags are effective tools for jobsite safety management in construction. The RFIDSIM system was installed on main server in the jobsite office. During the field trials, verification and validation tests were performed to evaluate the system. The verification aims to evaluate whether the system operates correctly according to the design and specification; and validation evaluates the usefulness of the system. The verification test was carried out by checking whether the RFIDSIM system can perform tasks as specified in the system analysis and design. The validation test was undertaken by asking selected case participators to use the system, and provide feedback by answering a questionnaire. Some comments for future improvements of RFIDSIM system were also obtained from the case participators through user satisfaction survey. Table 1 shows a comparison using a traditional paper-based inspection approach and the proposed system. The next section presents the detailed results of the performance evaluation and the user survey conducted during the field trials.

\begin{tabular}{llll}
\hline \multirow{2}{*}{ Item } & \multicolumn{1}{c}{ Traditional Approach } & Method & Proposed Approach \\
\cline { 2 - 3 } Inspection recording method & Paper forms & Used RFID-enabled smartphone to scan RFID tag \\
Inspection data search speed & Referring to Inspected item and checklist & Use electronic forms \\
Inspector location tracking & Paper forms & Real-time Update database \\
Is inspection on schedule? & Hard to check & The system record automatically \\
Inspection history management & Paper forms & Access the system and refer directly \\
Information Dissemination & Paper forms delivering & Access the system directly and share information &
\end{tabular}

Table 1. System Evaluation Result 


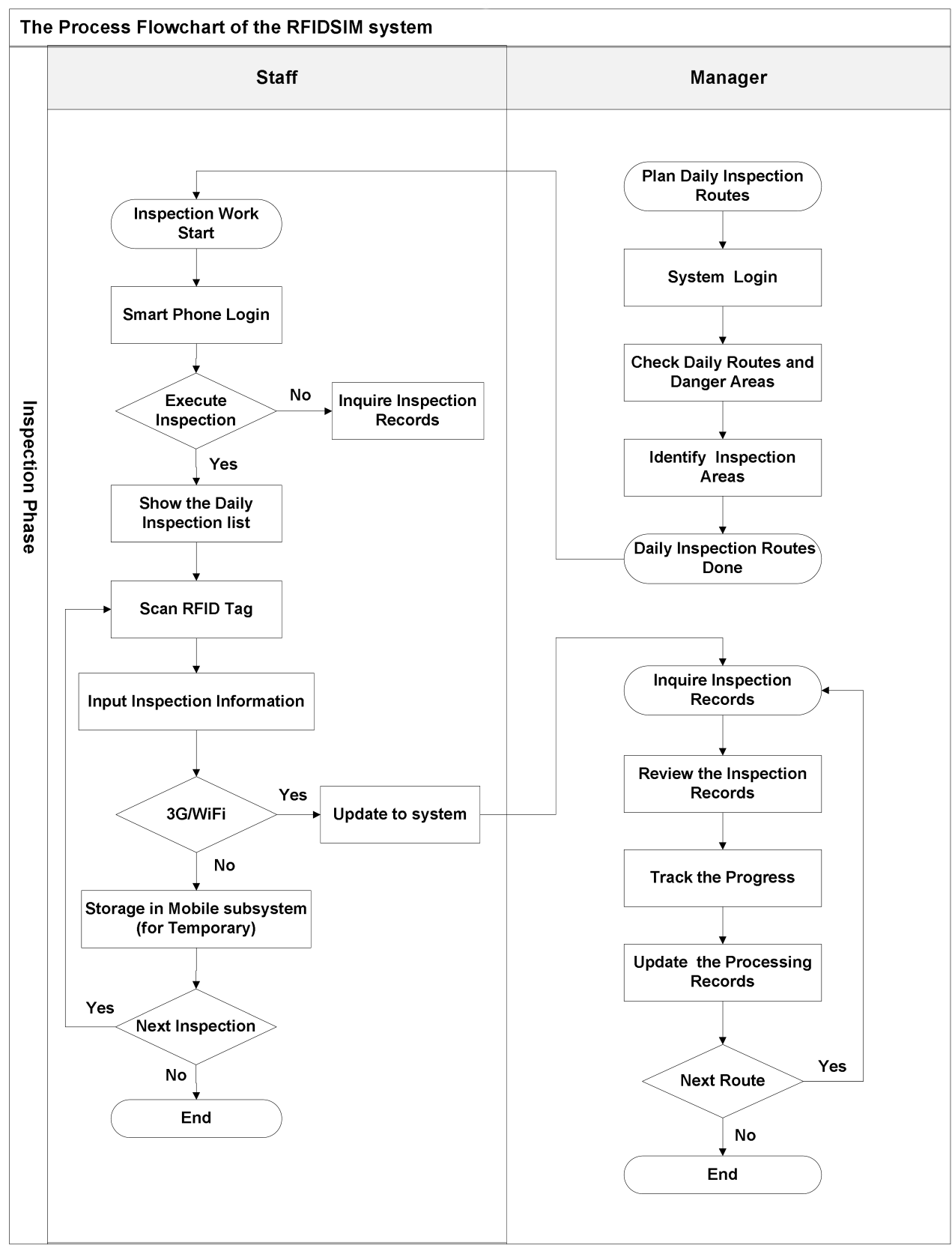

Figure 8. displayed the process flowchart of RFIDSIM system. 

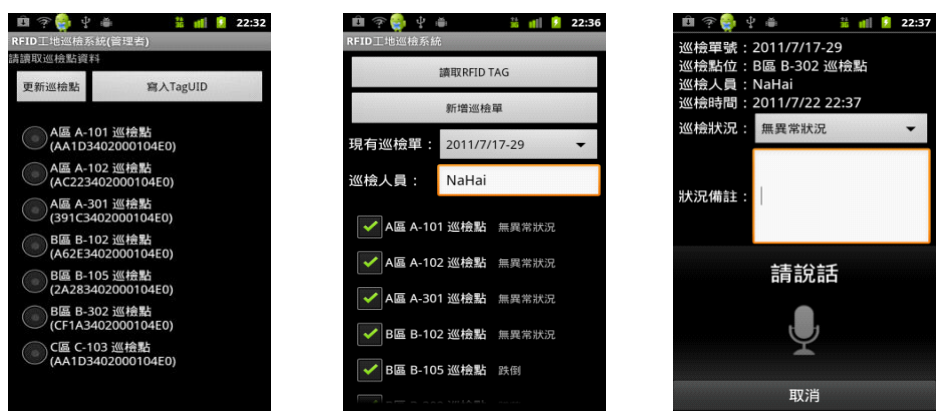

Figure 9. displayed safety staff used RFID-enabled smartphone to scan RFID tags and edited the description in the smartphone.

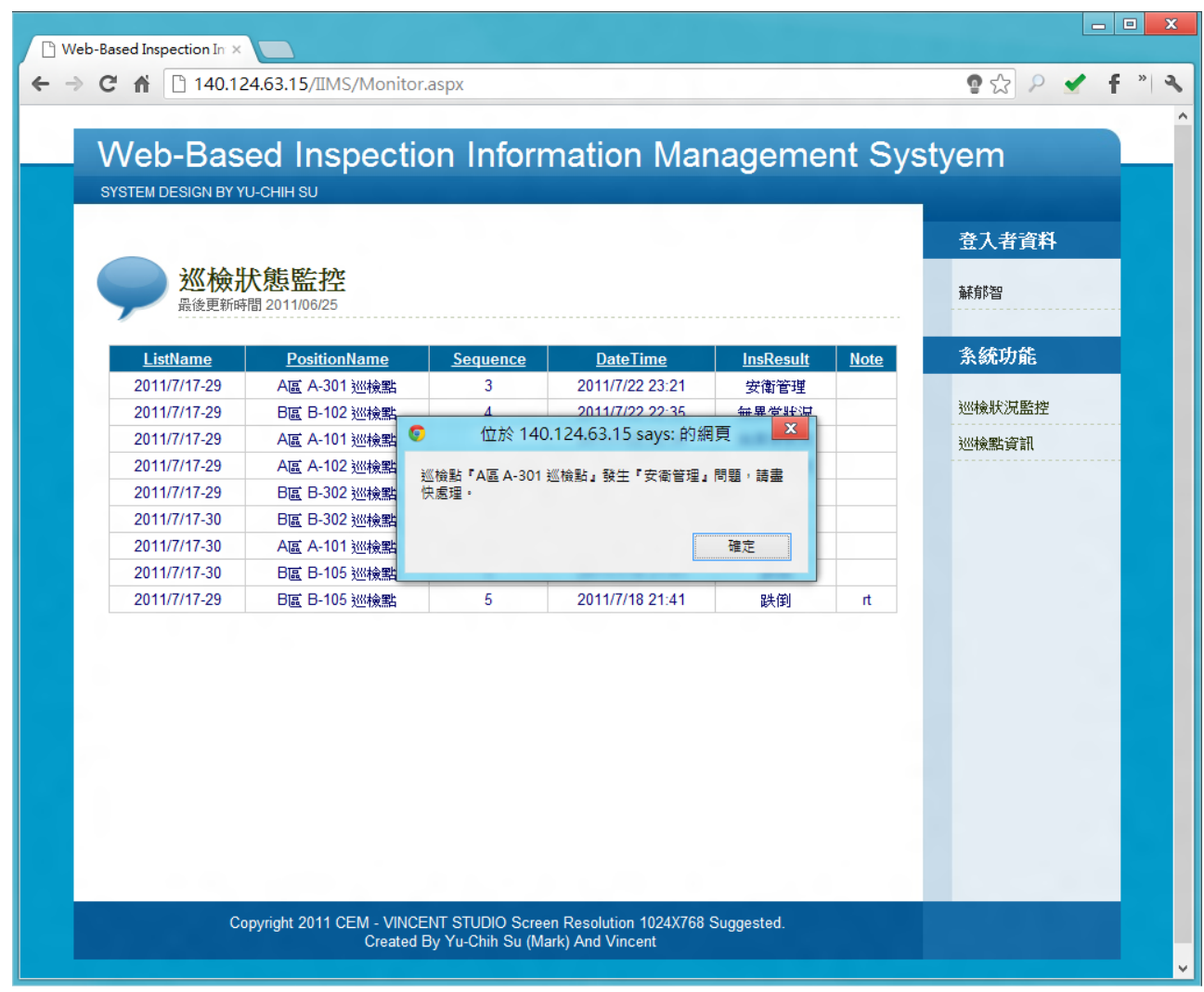

Figure 10. displayed project manager entered the RFIDSIM system and accessed the safety inspection result. 
Based on the result obtained from user satisfaction survey indicates that the RFIDSIM system is quite adaptable to the current jobsite safety management practices in construction jobsite, and is attractive to users. This result implies that the RFIDSIM system was well designed, and could enhance the current time-consuming jobsite safety inspection management process. Furthermore, safety staff members just scan the RFID tag and send them electronically to the RFIDSIM system. No additional work was required for any documentation or safety inspection analysis after the data collection.

The advantages and disadvantages of RFIDSIM system identified from the polite test studies application are identified. However, safety staff members' satisfaction survey agree that the RFIDSIM system is useful for improving the efficiency and effectiveness of automated data acquisition and information collection in important check locations, thus assisting safety managers and safety staff members in managing and monitoring the safety inspection processes of the building. Thus, HF passive tags are suited to jobsite safety management.

The use of RFID and web technology to collect and capture information significantly enhanced the efficiency of jobsite safety inspection processes in construction jobsite. Mobile RFID-enabled smartphone with NFC technology and tags are widely thought likely to improve in the future and significantly improving the safety inspection processes efficiency.

In the cost analysis, the HF tags adopted in this study cost under \$1 US dollars each in 2012. The cost of these tags is decreasing every year. The total cost of the equipment applied in this study was \$3250 US dollars (including RFID-enabled smartphone with NFC technology reader and one server personal computer). Even the reader initial cost is higher, but it is function expandable and really decreases human work. Experimental results demonstrate that RFIDSIM system can significantly enhance the safety inspection processes efficiency. The use of RFID significantly decreases the overall safety inspection operation time and human cost.

The findings of this polite test revealed several limitations of the RFIDSIM system. The following are inherent problems recognized during the case study.

- RFID tags attached to outdoor checkpoint are easily damaged because of external environmental pollution (such as dust, rain, etc.). Therefore, it is necessary to consider and enhance protection and waterproof of RFID tags.

- The cost of system implementation is high because of the non-permanent facilities of the site environment. The required cost increases because that most the temporary facilities, inspection checkpoints always change the location.

- The RFIDSIM is required by the WiFi wireless network or 3G communications to transfer data. Sometime web-based communications in the jobsite safety checkpoints locations are weak and cause information disconnection because of the poor environment (such as underground, corner, etc.).

\section{Conclusions}

This study presents a Mobile RFID-based safety inspection management (RFIDSIM) system that incorporates RFID technology and mobile devices to improve the effectiveness and con- 
venience of information flow during construction phase of construction project. The RFIDSIM system not only improves the acquisition of data on safety inspection result efficiency using RFID-enabled smartphones, but also provides a real time service platform during safety inspection progress. In the case study, plugging a RFID scanner into a smartphone creates a powerful portable data collection tool. Additionally, RFID readings increase the accuracy and speed of information search, indirectly enhancing performance and productivity. Safety staff members use RFID-enabled smartphones to enhance seamlessly inspection work processes at checkpoints locations, owing to its searching speed and ability to support detail information during the process. Meanwhile, on the server side, the RFIDSIM system offers a hub center to provide jobsite management division with real-time to monitor the jobsite safety progress. In a case study, the application of the RFIDSIM system helps to improve the process of jobsite safety inspection and management work for the construction jobsite in Taiwan. Based on experimental result, this study demonstrated that HF passive RFID technology has significant potential to enhance jobsite safety inspection and management work in construction management. The integration of real-time inspection information from jobsite safety checkpoints helps safety staff members to track and control the whole inspection management progress. Compared with current methods, the combined results demonstrate that, an RFIDSIM system can be a useful RFID-based jobsite safety inspection management platform by utilizing the RFID approach and web technology.

Building information modeling (BIM) is one of the most promising recent developments in the AEC industry. In the future, application of BIM can be considered and integrated for better and advanced jobsite safety inspection and management. Furthermore, the application of BIM will be a viable approach to jobsite safety management during the construction phase of a construction project. The BIM approach, which is utilized to retain visual status of safety condition in a digital format, facilitates effective safety management in the 3D CAD environment. The BIM provides users with an overview of current jobsite safety inspection result during a given construction project, such that users can track and manage jobsite safety inspection result virtually.

\section{Recommendations}

Recommendations for implementing the proposed system in the future are given below.

- Cost is a currently significant factor limiting the widespread use of RFID tags in the construction industry. Passive tags are cheaper than active tags. Therefore, passive tags are suited to jobsite safety management.

- The smartphone screen is not large enough for operating the RFIDSIM system fluently. The system should be redesigned and developed to be suitable for the smartphone screen.

- In this study, the major characteristic is that users can apply the RFIDSIM system without purchasing additional RFID reader. Currently, this system is developed for Google Android system and will be developed for Apple i-phone system in the future. 


\section{Author details}

Yu-Cheng Lin, Yu-Chih Su, Nan-Hai Lo, Weng-Fong Cheung and Yen-Pei Chen

National Taipei University of Technology, Civil Engineering, Taiwan

\section{References}

[1] Baldwin, A. N., Thorpe, A. and Alkaabi, J. A. (1994), "Improved material management through bar-code: results and implications of a feasibility study," Proceedings of the institution of Civil Engineers, Civil Engineering, 102(6), 156-162.

[2] Chin, S., Yoon, S., Choi, C., and Cho, C. (2008). "RFID+4D CAD for progress management of structural steel works in high-rise buildings,"Journal of Computing in Civil Engineering, ASCE, 22(2), 74-89.

[3] Elghamrawy, T. and Boukamp, F. (2010). "Managing construction information using RFID-based semantic contexts," International Journal of Automation in Construction, 19(8), 1056-1066.

[4] Elzarka, H. M. and Bell, L. C. (1997), “Development of Pen-Based Computer Field Application," Journal of Computing in Civil Engineering, ASCE, 11(2), 140-143.

[5] Ergen, E., Akinci, B., and Sacks, R. (2006) "Tracking and locating components in a precast storage yard utilizing radio frequency identification technology and GPS," International Journal of Automation in Construction, doi:10.1016/j.autcon. 2006.07.004.

[6] Fayek, A., AbouRizk, S. and Boyd, B. (1998), "Implementation of automated site data collection with a medium-size contractor," in Proc. ASCE Computing in Civil Engineering, Boston, MA, 454-6.

[7] Goodrum, P. M., McLaren, M. A., and Durfee, A. (2006) "The application of active radio frequency identification technology for tool tracking on construction job sites," International Journal of Automation in Construction, 15(3), 292-302.

[8] Jaselskis, E. J. and Anderson, M. R. (1995). "Radio-Frequency Identification Applications in Construction Industry," Journal of Construction Engineering and Management, 121(2), 189-196.

[9] Jaselskis, E. J. and El-Misalami, Tarek (2003). "Implementing Radio Frequency Identification in the Construction Process," Journal of Construction Engineering and Management, 129(6), 680-688.

[10] Lahiri, Sandip (2005), RFID Sourcebook, Prentice Hall PTR. 
[11] Lee, Ung-Kyun, Kang, Kyung-In, and Kim, Gwang-Hee (2006). "Improving Tower Crane Productivity Using Wireless Technology." Journal of Computer-Aided Civil and Infrastructure Engineering, Vol. 21, pp.594-604.

[12] Manish Bhuptani and Shahram Moradpour (2005), RFID Field Guide : Deploying Radio Frequency Identification Systems, Prentice Hall PTR.

[13] McCullouch, B. G. (1997), "Automating field data collection in construction organizations," in Proc. ASCE Construction Congress V, Minneapolis, MN, 957-63

[14] Pena-Mora, F. and Dwivedi, G. D. (2002), “Multiple Device Collaborative and Real Time Analysis System for Project Management in Civil Engineering," Journal of Computing in Civil Engineering, ASCE, 16(1), 23-38.

[15] Song, J., Haas, C. T. and Caldas, C. (2006). "Tracking the Location of Materials on Construction Job Sites," Journal of Construction Engineering and Management, 132(9), 680-688.

[16] Song, J., Haas, C. T., Caldas, C., Ergen, Esin, and Akinci, B. (2006). “Automating the task of tracking the delivery and receipt of fabricated pipe spools in industrial projects," International Journal of Automation in Construction, 15(2), 166-177.

[17] Sunkpho, Jirapon and Garrett, J. H., Jr. (2003), “Java Inspection Framework: Developing Field Inspection Support System for Civil Systems Inspection," Journal of Computing in Civil Engineering, ASCE, 17(4), 209-218.

[18] Tserng, H. P., Dzeng, R. J., Lin, Y. C. and Lin, S. T. (2005). “Mobile Construction Supply Chain Management Using PDA and Bar Codes." Journal of Computer-Aided Civil and Infrastructure Engineering, Vol. 20, pp.242-264.

[19] Wang, L. C., Lin, Y. C. and Lin, P. H. (2006). “Dynamic Mobile RFID-based Supply Chain Control and Management System in Construction." International Journal of Advanced Engineering Informatics - Special Issue on RFID Applications in Engineering, Vol. 21 (4), pp.377-390.

[20] Ward, M. J., Thorpe, A. and Price, A. D. F. (2003), “SHERPA: mobile wireless data capture for piling works, "Computer-Aided Civil and Infrastructure Engineering, 18, 299-314.

[21] Yagi, Junichi, Arai, Eiji and Arai, Tatsuo (2005). "Construction automation based on parts and packets unification," International Journal of Automation in Construction, 12(1), 477-490.

[22] Yin, Y.L., Tserng, H. P., Wang, J.C. and Tsai, S. C. (2009). "Developing a precast production management system using RFIF Technology," International Journal of Automation in Construction, 18(5), 677-691. 